\title{
Implementasi Algoritma Hebb Rule Pada Diagnosa Penyakit Kolik Abdomen Pada Orang Dewasa
}

\author{
Etty Diana Manurung, Berto Nadeak, Eferoni Ndruru \\ Program Studi Teknik Informatika, STMIK Budi Darma, Medan, Indonesia \\ Email: 1dianaetty6@gmail.com \\ Submitted 16-03-2020; Accepted 20-04-2020; Published 26-04-2020
}

\begin{abstract}
Abstrak
Pada era globalisasi sekarang ini, perkembangan komputer pada bidang kesehatan sudah semakin pesat. Sistem komputerisasi sangat diperlukan terutama dalam menanganni suatu penyakit. Karena terkadang dokter, perawat susah mengetahui jenis penyakit yang diderita oleh pasinnya baik orang dewasa, anak, dan usia lanjut tanpa adanya sistem komputerisasi yang baik. Penyakit kolik abdomen misalnya. Kolik abdomen merupakan suatu penyakit dimana rasa tidak enak di dalam rongga mulut antara batas paha dan batas rusuk dada. Penyakit ini disebabkan oleh beberapa faktor, misalnya, makan terlaqlu kenyang, makan banyak mengandung asam, pedas dan juga banyak minum alkohol. Dan biasanya terjadi pada orang dewasa. Dimana gejala gejalnya seperti mual-mual, muntah dan usus bising serta kentut yang berlebihan. Dengan gejala tersebut, yang menjadi suatu kendali bahwasanya seseorang itu mengalami penyakit kolik abdomen. Oleh sebab iu penulis membuat penelitian tentang implementasi algoritma hebb rule pada diagnosa penyakit kolik abdomen. Algoritma hebb rule merupakan suatu metode pembelajaran yang sederhana dan tidak rumit dalam pengerjaannya, dengan tujuan untuk meminimalkan resiko masalah penyakit yang terjadi pada pasien terkhusunya orang dewasa.
\end{abstract}

Kata Kunci: Jaringan Syaraf Tiruan, Kolik Abdomen, Hebb Rule

Abstract

In the current era of globalization, the development of computers in the health sector has become increasingly rapid. Computerized systems are needed especially in handling a disease. Because sometimes doctors, nurses find it difficult to know the type of illness suffered by adults, children and the elderly without a good computerized system. Abdominal colic, for example. Abdominal colic is a disease where there is an unpleasant feeling in the oral cavity between the thigh border and the chest rib border. This disease is caused by several factors, for example, eating is already full, eating a lot of acid, spicy and also drinking lots of alcohol. And usually occurs in adults. Where symptoms are symptoms such as nausea, vomiting and noisy intestines and excessive farts. With these symptoms, which becomes a control that a person has abdominal colic disease. Therefore the author made a study of the implementation of the HB rule on the diagnosis of abdominal colic disease. Theebb rule algorithm is a simple and uncomplicated learning method in the process, with the aim of minimizing the risk of disease problems that occur in patients, especially adults.

Keywords: Artificial Neural Network Colic Abdomen, Hebb Rule

\section{PENDAHULUAN}

Di dalam dunia kesehatan, penyakit merupakan suatu musuh yang dapat di alami oleh siapa saja, termasuk pada manusia. Biasanya, penyakit berasal dari faktor lingkungan, kuranganya kebersihan diri sendiri dan bahkan makanan yag dibeli dari luar. Sehingga untuk mengatasinya, seseorang biasanya akan membeli obat dari apotik atau tempat jual obat yang terdekat. Jika keadaanya sudah semakin parah, maka orang tersebut akan pergi ke dokter untuk periksakan diri. Dokter akan memeriksa pasien dan segera membuat resep obatnya.

Salah satu penyakit yang umum terjadi pada manusia adalah penyakit kolik abdomen. Penyakit kolik abdomen adalah istilah yang digunakan untuk menggambarkan nyeri spasmodik parah pada perut yang disebabkan oleh distensi (menegang), obstruksi (sumbatan) atau perandangan pada organ tubuh yang memiliki otot polos, misalnya usus, kandung empedu, ginjal, dan lain-lain. Rasa sakit ini dapat muncul mendadak pada orang dewasa, bisa juga berkembang secara bertahap dan semakin kronis. penyebabnya cepat diketahui misalnya, makan terlalu kenyang, makanan yang terlalu banyak asam, pedas, dan kebanyakan minuman yang beralkohol. Nyeri abdomen juga dapat terjadi karena diare atau sembelit. Banyak wanita yang mengalami nyeri pada daerah pinggul dan perut bagian bawah pada waktuhaid.Nyeri dapat terjadi sebelum atau selama haid,atau pada saat ovulasi. Dari gejala-gejala tersebut timbul masalah yang sering terjadi dalam penanganan penyakit itu sendiri. Terkadang dokter tidak dapat menentukan penyakit apa yang diderita pasien, karena gejala-gejala tersebut bisa juga terjadi pada penyakit lain. Sehingga untuk menangani masalah yang terjadi, diperlukan sebuah solusi bagimana mengetahu penangan secara cepat dan akurat terhadap pasien.

Perkembangan ilmu pengetahuan dan teknologi dapat melakukan pengambilan keputusan dalam mendiagnosa penyakit yang dialami oleh manusia. Sehingga di perlukan tenaga medis dan bahkan penyakit tersebut sangat sulit dalam menanganinya. Dengan ilmu pengetahuan yang kurang, dapat menyebabkan penanganan yang salah terhadap suatu penyakit. Dimana suatu saat dapat bisa jadi semakin parah dan bahkan mengakibatkan kematian. Oleh sebab itu, di butuhkan suatu aplikasi untuk mendiagnosa gejala-gejala penyakit kolik abdomen pada orang dewasa yang dirasakan oleh pasien itu sendiri.

Sebelumnya metode ini sudah pernah diteliti dengan judul "Pengenalan Huruf Braille Berbasis Jaringan Syaraf Tiruan Metode Hebb Rule" [1]. Hebb rule adalah metode pembelajaran yang paling sederhana. Pada metode ini pembelajaran dilakukan dengan cara memperbaiki nilai bobot sedemikian rupa sehingga jika ada 2 neuron yang terhubung, dan keduanya pada kondisi 'hidup' (on) pada saat yang sama, maka bobot antara keduanya dinaikkan. Apabila data direpresentasikan secara bipolar, maka perbaikan bobotnya. Oleh sebab itu metode tersebut sangat berguna dalam memecahkan suatu masalah yang terjadi. Masalah yang dihadapi menjadi tujuan penelitian itu sendiri. 


\section{METODE PENELITIAN}

\subsection{Jaringan Syaraf Tiruan}

Jaringan syaraf tiruan merupakan suatu sistem pemrosesan informasi yang memiliki karakteristiik-karateristik menyerupai jaringan syaraf biologi. Hal yang sama di utarakan oleh Simon,Haykin, yang menyatakan bahwa JST adalah sebuah mesin yang dirancang untuk memodelkan cara otak manusia mengerjakan fungsi atau tugas-tugas tertentu. Secara prinsip, jaringan syaraf tiruan dapat melakukan komputasi terhadap semua fungsi yang dapat dihitung.

Dalam praktiknya, jaringan syaraf tiruan sangat berguna bagi klasifikasi dan permasalahan-permasalahan yang dapat menolerir ketidaktepatan, yang memiliki banyak data pelatihan, namun memiliki aturan-aturan yang tidak dapat diaplikasikan secara mudah. Adapun ciri ciri sistem JST adalah sebagai beirkut :

1. Pemrosesan inforasi bersifat lokal

2. Memori terbagi atas LTM (Long Term Memory) yang merupakan bobot keterhubungan dan STM( Short Term Memory) yang dihubungkan neoran ke sinyal yang dijalankan.

3. Tegangan pembobotan dapat berubah menurut pengalaman.

4. Neurontranmitter dan Synaptic dapat bersfat penyalaan atau pemadaman.

\subsection{Algoritma Hebb Rule}

Algoritma hebb rule adalah metode pembelajaran yang paling sederhana. Adapaun menjadi dasar algoritma hebb rule adalah bahwa apabila dua neuron yang dihubungkan dengan sinapsis secara serentak menjadi aktif (sama-sama bernilai positif atau negatif), maka kekuatan sinapsisnya meningkat. Sebaliknya, apabila kedua neuron aktif secara tidak sinkron (salah satu bernilai positif dan yang lain bernilai negatif), maka kekuatan sinapsisnya akan melemah, adapun rumus perbaikan bobotnya adalah:

dengan:

$$
w i(\text { baru })=w i(l a m a)+x i * y
$$

wi : bobot data input ke-i;

xi : input data ke-i.

y : output data.

1. Algoritma pelatihan Hebb Rule:

a. Insialisasi bobot dan bias:

$$
\begin{aligned}
& \mathrm{W}_{\mathrm{i}}=0 ; \text { dengan } \mathrm{i}=1,2, \ldots, \mathrm{n} ; \\
& \mathrm{b}=0
\end{aligned}
$$

b. Untuk setiap pasangan input $-\operatorname{target}(\mathrm{s}-\mathrm{t})$, lakukan;

1. Set aktivitas unit input: $\quad \mathrm{x}_{\mathrm{i}}=\mathrm{si}_{\mathrm{i}} ;(\mathrm{i}=1,2, \ldots, \mathrm{n})$

2. Set aktivitas unit input: $\quad y_{j}=t_{j} ;(i=1,2, \ldots, m)$

c. Perbaiki bobot menurut persamaan berikut:

$\mathrm{W}_{\mathrm{i}}($ baru $)=\mathrm{w}_{\mathrm{i}}($ lama $)+\mathrm{x}_{\mathrm{i}}{ }^{*} \mathrm{y}_{\mathrm{j}}$

( $i=1,2, \ldots, n ;$ dan $j=1,2, \ldots, m$ )

d. Perbaiki biasa menurut persamaan berikut:

$\mathrm{b}($ baru $)=\mathrm{b}($ lama $)+\mathrm{y}$

\subsection{Penyakit Kolik Abdomen}

Kolik abdomen adalah gangguan pada aliran normal usus sepanjang tratus intestinal. Rasa nyeri pada perut yang sifatnya hilang timbul dan bersumber dari organ yang terdapat dalam abdomen (perut) hal yang mendasari penyakit ini adalah infeksi pada organ di dalam perut (mencret, radang kandung empedu, radang kandung kemih), sumbatan dari organ perut (batu empedu, batu ginjal). Rasa sakit ini dapat muncul mendadak pada orang dewasa, bisa juga berkembang secara bertahap dan semakin kronis. penyebabnya cepat diketahui misalnya, makan terlalu kenyang, makanan yang terlalu banyak asam, pedas, dan kebanyakan minuman yang beralkohol. Nyeri abdomen juga dapat terjadi karena diare atau sembelit. Banyak wanita yang mengalami nyeri pada daerah pinggul dan perut bagian bawah pada waktu haid. Nyeri dapat terjadi sebelum atau selama haid,atau pada saat ovulasi [4].

\section{HASIL DAN PEMBAHASAN}

Analisa bertujuan untuk mengetahui kebutuhan perangkat lunak pada jaringan saraf tiruan yang akan dibangun dan yang paling utama adalah berguna dalam penguraian konsep kedalam bagian-bagian yang lebih sederhana sehingga struktur logisnya jadi lebih jelas dan akurat. Didalam analisa ini dilakukan pengumpulan data serta pengetahuan yang dilakukan oleh jaringan saraf tiruan, sehingga sangat dapat didefinisikan dengn baik dan jelas.

Kolik abdomen adalah gangguan pada aliran normal usus sepanjang tratus intestinal. Rasa nyeri pada perut yang sifatnya hilang timbul dan bersumber dari organ yang terdapat dalam abdomen (perut) hal yang mendasari penyakit ini adalah infeksi pada organ di dalam perut (mencret, radang kandung empedu, radang kandung kemih), sumbatan dari organ perut (batu empedu, batu ginjal). Rasa sakit ini dapat muncul mendadak pada orang dewasa, bisa juga berkembang secara bertahap dan semakin kronis. penyebabnya cepat diketahui misalnya, makan terlalu kenyang, makanan yang terlalu banyak asam, 
pedas, dan kebanyakan minuman yang beralkohol. Nyeri abdomen juga dapat terjadi karena diare atau sembelit. Banyak wanita yang mengalami nyeri pada daerah pinggul dan perut bagian bawah pada waktu haid. Nyeri dapat terjadi sebelum atau selama haid, atau pada saat ovulasi. Dengan adanya perancangan implementasi diagnosa penyakit kolik dapat memberikan pengetahuan luas dalam pengertian, penyebab dan gejala-gejalnya. Gejala - gejala penyakit kolik disebabkan oleh makan yang sembarang dan banyak minuman yang beralkohol. Untuk membantu mencegah masalah tersebut, maka pemecahan masalah adalah dengan merancang suatu jaringan syaraf tiruan untuk mendiagnosa penyakit tersebut

Berdasarkan hasil konsultasi dengan seorang dokter, ada beberapa gejala dari penyakit kolik abdomen. Adapun gejala gejala penyakit kolik abdomen adalah sebagai berikut:

Tabel 1. Gejala Penyakit Kolik Abdomen

\begin{tabular}{cll}
\hline No & Kode & \multicolumn{1}{c}{ Gejala } \\
\hline 1 & G1 & Nyeri ulu hati \\
2 & G2 & Mual \\
3 & G3 & Tubuh terasa lemas dan panas \\
4 & G4 & Terasa perih bagian perut \\
5 & G5 & Nyeri punggung \\
6 & G6 & Perut kembung \\
7 & G7 & Gangguan buang air kecil \\
8 & G8 & Diare \\
9 & G9 & Distensi berat \\
10 & G10 & Distensi ringan \\
11 & G11 & Peningkatan bising usus \\
12 & G12 & Perut terasa panas \\
13 & G13 & Tidak bisa buang angin dan BAB \\
14 & G14 & Kehilanagan nafsu makan \\
15 & G15 & Nyeri di daerah dada \\
16 & G16 & Kram perut \\
17 & G17 & Muntah - muntah \\
\hline
\end{tabular}

Tabel 2. Tabel Aturan

\begin{tabular}{cllll}
\hline No & $\begin{array}{c}\text { Kode } \\
\text { Aturan }\end{array}$ & $\begin{array}{c}\text { Kode } \\
\text { Penyakit }\end{array}$ & Nama Penyakit & \multicolumn{1}{c}{ Rule } \\
\hline 1 & K001 & P001 & Koelitiasis & G2 AND G12 AND G14 \\
2 & K002 & P002 & Ileus & G2 AND G13 AND G14 AND G17 \\
3 & K003 & P003 & Dispepsia & G2 AND G3 ANDG6 AND G14 \\
4 & K004 & P004 & Apendiscitis & G1 AND G4 AND G5 AND G6 AND G7 AND G8 \\
& & & AND G9 AND G10 AND G12 AND G14 AND G17 \\
\hline
\end{tabular}

Proses penentuan jenis penyakit pada pasien dilakukan secara proses manual, artinya bahwa data gejala penyakit pada pasien dicatat, dilakukan pemeriksaan kemudian disimpulkan jenis penyakit dengan melihat kembali jenis gejala yang tunjukkan oleh pasien, kemudian pasien melakukan penanganan atau tindakan ke dokter spesialis.

Tabel 3. Tabel penyakit

\begin{tabular}{|c|c|c|c|}
\hline No & Nama Penyakit & Keterangan & Solusi \\
\hline 1 & $\begin{array}{l}\text { Kolelitiasis } \\
\text { (Batu empedu) }\end{array}$ & $\begin{array}{l}\text { Batu empedu adalah timbunan krista di dalam } \\
\text { saluran empedu atau di dalam saluran } \\
\text { empedu. Batu yang di dalam kandung } \\
\text { empedu disebut kolelitiasis, sedangkan batu } \\
\text { di dalam saluran empedu disebut kolesistitis. } \\
\text { Batu empedu lebih banyak ditemukan pada } \\
\text { wanita dan faktor resikonya adalah usia } \\
\text { lanjut, kegemukan (obesitas), diet tinggi } \\
\text { lemak, faktor keturunan. }\end{array}$ & $\begin{array}{l}\text { Batu empedu bisa ditangani dengan } \\
\text { obat-obatan hingga operasi } \\
\text { pengangkatan kantong empedu. Walau } \\
\text { fungsi organ ini penting, tubuh kita tetap } \\
\text { bisa bertahan tanpa memilikinya. Tanpa } \\
\text { kantong empedu, hati akan tetap } \\
\text { mengeluarkan cairan empedu yang } \\
\text { membantu dalam pencernaan lemak. }\end{array}$ \\
\hline 2 & $\begin{array}{l}\text { Ileus } \\
\text { (Penyumbatan usus) }\end{array}$ & $\begin{array}{l}\text { Ileus adalah nama lain dari penyakit } \\
\text { penyumbatan di usus, dimana usus } \\
\text { mengalami gangguan berupa penyumbatan } \\
\text { hingga menyebabkan isi dalam usus tidak } \\
\text { dapat bergerak karena ususnya tertutup atau } \\
\text { tersumbat. Hal ini mengakibatkan } \\
\text { terhentinya gerakan di usus sehingga } \\
\text { makanan tidak bisa lewat ke saluran cerna. }\end{array}$ & $\begin{array}{l}\text { Bagi penderita ileus biasanya tidak } \\
\text { memerlukan tindakan operasi, penderita } \\
\text { hanya perlu mengkonsumsi jenis } \\
\text { makanan yang berserat rendah agar bisa } \\
\text { dengan mudah dicerna. }\end{array}$ \\
\hline
\end{tabular}




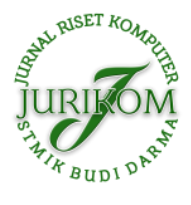

3 Dispepsia(Maag)
4

Apendiscitis

(Usus buntu)
Dispepsia adalah kumpulan gejala yang muncul dan dapat menimbulkan ketidaknyaman pada perut bagian atas atau dada.Dispepsia biasanya disebabkan oleh gaya hidup seseorang yang cenderung tidak sehat. Selain itu, dispepsia juga bisa dikaitkan dengan infeksi, kondisi pencernaan atau kelebihan asam lambung.

Usus buntu yaang menempel pada usus besar ini memiliki panjang sekitar 5 centimeter hingga $10 \mathrm{~cm}$. Ini adalah bagian dari morfologi tubuh secara natural dan berfungsi sebagai wadah bakteri usus yang menguntungkan tubuh.

Disebut dengan usus buntu
Perubahan pola makan ini biasanya dapat dilakukan dengan mengonsumsi lebih sedikit makanan berlemak dan pedas, serta kurangi kafein, alkohol, dan cokelat. Selain itu, tidur minimal 7 jam setiap malam juga dapat membantu mengurangi gangguan pencernaan ringan.Berolahraga secara teratur dan berhenti merokok juga merupakan perubahan gaya hidup yang penting dalam mengobati gangguan pencernaan. Sebagai solusinya disarankan memakan bawang putih 2-3 siung perhari, mengolesi minyak jarak 3 x seminggu, meminum jahe 2-3 hari, serta makanan tinggi serat, seperti tomat, brokoli, mentimun dan wortel

Metode hebb rule merupakan suatu metode dengan aturan pelatihan yang paling sederhanaa, dan secara umum banyak digunakan paada jaringan syaraf tiruan. Aturan pelatihan metode ini adalah, jika kedua syaraf kedua-duanya "on" maka bobot neuronnya bertambah. Dengan menggunakan metode ini, pembelajaran dilakukan dengan cara memperbaiki nilai bobot sehingga jika ada 2 neuron terhubung dengan kedua-duanya dalam keadaan "on" pada saat yang bersamaan, maka bobot kedua-duanya dinaikkan. Dan apabila data diperesentasikan secara bipolar, maka perbaikan bobotnya adalah sebagai berikut

Wi (baru) $=$ wi (lama) $+\mathrm{Xi} * \mathrm{y}$

Dengan :

Wi : bobot data input ke -i;

$\mathrm{Xi}$ : input data ke-i

Y : output data

Misalkan vektor yang hendak digunakan adalah vektor x, maka Algoritma adalah sebaagai berikut :

1. Inisialisasi semua bobot $=0$ dan $b=0$

2. Set masukan $\mathrm{Xi}=\mathrm{Si}(\mathrm{i}=1,2, \ldots, \mathrm{j} ; \mathrm{j}=$ jumlah input $)$

3. Untuk semua Xi:

a. Perbaiki bobot: $\mathrm{Wi}($ baru $)=\mathrm{Wi}($ lama $)+\Delta w$ dengan $\Delta w=\mathrm{Xi} \mathrm{t}$

b. Perbaiki bias: $\mathrm{b}($ baru $)=\mathrm{b}($ lama $)+\Delta b$ dengan $\Delta b=\mathrm{t}$

4. Hitung: $\operatorname{net}(\mathrm{n})=\sum_{i=1}^{j} x i w i+b ; \mathrm{j}=$ jumlah input

5. Tentukan nilai $\mathrm{f}(\mathrm{n})$ :

a. Untuk target biner:

$$
\begin{aligned}
\mathrm{f}(\mathrm{n}) & =1, \mathrm{n} \geq 0 \\
& =0, \mathrm{n}<0
\end{aligned}
$$

b. Untuk target bipolar:

$$
\begin{aligned}
\mathrm{f}(\mathrm{n}) & =1, \mathrm{n} \geq 0 \\
& =-1, \mathrm{n}<0
\end{aligned}
$$

Adapun contoh kasusnya adalah pada pasien yang menderita penyakit Kolik Abdomen. Penyakit ini disebabkan oleh: Perhitungan pelatihan Hebb Rule :

Tabel 4. Tabel Data Training

\begin{tabular}{ccccccccccccccccccc}
\hline X1 & X2 & X3 & X4 & X5 & X6 & X7 & X8 & X9 & X10 & X11 & X12 & X13 & X14 & X15 & X16 & X17 & b & Target \\
\hline 0 & 1 & 0 & 0 & 0 & 0 & 0 & 0 & 0 & 0 & 0 & 1 & 0 & 1 & 0 & 0 & 0 & 1 & 1 \\
0 & 1 & 0 & 0 & 0 & 0 & 0 & 0 & 0 & 0 & 0 & 0 & 1 & 1 & 0 & 0 & 1 & 1 & 1 \\
0 & 1 & 1 & 0 & 0 & 1 & 0 & 0 & 0 & 0 & 0 & 0 & 0 & 1 & 0 & 0 & 0 & 1 & 1 \\
1 & 0 & 0 & 1 & 0 & 0 & 0 & 0 & 0 & 1 & 0 & 1 & 0 & 1 & 0 & 0 & 1 & 1 & 1 \\
\hline
\end{tabular}

Dinyatakan sebagai berikut:

Inisialisasi bobot dan bias: $\mathrm{W}_{1}=0, \mathrm{~W}_{2}=0, \mathrm{~W}_{3}=0, \mathrm{~W}_{4}=0, \mathrm{~W}_{5}=0, \mathrm{~W}_{6}=0, \mathrm{~W}_{7}=0, \mathrm{~W}_{8}=0, \mathrm{~W}_{9}=0, \mathrm{~W}_{10}=0, \mathrm{~W}_{11}=0, \mathrm{~W}_{12}=0$, $\mathrm{W}_{13}=0, \mathrm{~W}_{14}=0, \mathrm{~W}_{15}=0 \mathrm{~W}_{16}=0, \mathrm{~W}_{17}=0$

1. Pola hubungan masukan - target

Tabel 5. Pola hubungan masukan - target 


\begin{tabular}{|c|c|c|c|c|c|c|c|c|c|c|c|c|c|c|c|c|c|c|}
\hline X1 & $\mathbf{X} 2$ & X3 & X4 & X5 & X6 & $\mathbf{X} 7$ & X8 & X9 & X10 & X11 & X12 & X13 & X14 & X15 & X16 & X17 & b & $\mathbf{T}$ \\
\hline 0 & 1 & 0 & 0 & 0 & 0 & 0 & 0 & 0 & 0 & 0 & 1 & 0 & 1 & 0 & 0 & 0 & 1 & 1 \\
\hline 0 & 1 & 0 & 0 & 0 & 0 & 0 & 0 & 0 & 0 & 0 & 0 & 1 & 1 & 0 & 0 & 1 & 1 & 1 \\
\hline 0 & 1 & 1 & 0 & 0 & 1 & 0 & 0 & 0 & 0 & 0 & 0 & 0 & 1 & 0 & 0 & 0 & 1 & 1 \\
\hline 1 & 0 & 0 & 1 & 0 & 0 & 0 & 0 & 0 & 1 & 0 & 1 & 0 & 1 & 0 & 0 & 1 & 1 & 1 \\
\hline
\end{tabular}

2. Hasil pelatihan:

Tabel 6. Pelatihan

\begin{tabular}{|c|c|c|c|c|c|c|c|c|c|c|c|c|c|c|c|c|c|}
\hline \multicolumn{17}{|c|}{ Masukan } & \multirow{2}{*}{$\begin{array}{c}\text { Target } \\
\text { T }\end{array}$} \\
\hline X1 & $\mathbf{X} 2$ & $\mathbf{X 3}$ & X4 & X5 & X6 & $\mathbf{X} 7$ & X8 & X9 & $\mathbf{X 1 0}$ & X11 & X12 & X13 & X14 & X15 & X16 & X17 & \\
\hline 0 & 1 & 0 & 0 & 0 & 0 & 0 & 0 & 0 & 0 & 0 & 1 & 0 & 1 & 0 & 0 & 0 & 1 \\
\hline 0 & 1 & 0 & 0 & 0 & 0 & 0 & 0 & 0 & 0 & 0 & 0 & 1 & 1 & 0 & 0 & 1 & 1 \\
\hline 0 & 1 & 1 & 0 & 0 & 1 & 0 & 0 & 0 & 0 & 0 & 0 & 0 & 1 & 0 & 0 & 0 & 1 \\
\hline 1 & 0 & 0 & 1 & 0 & 0 & 0 & 0 & 0 & 1 & 0 & 1 & 0 & 1 & 0 & 0 & 1 & 1 \\
\hline
\end{tabular}
berikut :

Dari hasil pelatihan maka, akan mengalami perubahan pada pembobotn nilai. Adapun perubahannya adalah sebagai

Tabel 7. Perubahan Bobot

\section{Perubahan Bobot}

$\Delta \mathbf{w}=\mathbf{x i}{ }^{*} \mathbf{t}$

\begin{tabular}{|c|c|c|c|c|c|c|c|c|c|c|c|c|c|c|c|c|c|}
\hline $\begin{array}{c}\Delta \mathbf{w} \\
\mathbf{1} \\
\end{array}$ & $\begin{array}{c}\Delta \mathbf{w} \\
\mathbf{2} \\
\end{array}$ & $\begin{array}{c}\Delta \mathbf{w} \\
\mathbf{3}\end{array}$ & $\begin{array}{c}\Delta w \\
4\end{array}$ & $\begin{array}{c}\Delta w \\
5 \\
\end{array}$ & $\begin{array}{c}\Delta w \\
6\end{array}$ & $\begin{array}{c}\Delta w \\
7 \\
\end{array}$ & $\begin{array}{c}\Delta w \\
8 \\
\end{array}$ & $\begin{array}{c}\Delta w \\
9 \\
\end{array}$ & $\begin{array}{c}\Delta w 1 \\
0 \\
\end{array}$ & $\begin{array}{c}\Delta \mathrm{w} 1 \\
1 \\
\end{array}$ & $\begin{array}{c}\Delta \mathrm{w} 1 \\
2 \\
\end{array}$ & $\begin{array}{c}\Delta \mathrm{w} 1 \\
\mathbf{3} \\
\end{array}$ & $\begin{array}{c}\Delta \mathrm{w} 1 \\
4 \\
\end{array}$ & $\begin{array}{c}\Delta \mathrm{w} 1 \\
5 \\
\end{array}$ & $\begin{array}{c}\Delta \mathrm{w} 1 \\
6 \\
\end{array}$ & $\begin{array}{c}\Delta \mathrm{w} 1 \\
7 \\
\end{array}$ & b \\
\hline 0 & 1 & 0 & 0 & 0 & 0 & 0 & 0 & 0 & 0 & 0 & 1 & 0 & 1 & 0 & 0 & 0 & 1 \\
\hline 0 & 1 & 0 & 0 & 0 & 0 & 0 & 0 & 0 & 0 & 0 & 0 & 1 & 1 & 0 & 0 & 1 & 1 \\
\hline 0 & 1 & 1 & 0 & 0 & 1 & 0 & 0 & 0 & 0 & 0 & 0 & 0 & 1 & 0 & 0 & 0 & 1 \\
\hline 1 & 0 & 0 & 1 & 0 & 0 & 0 & 0 & 0 & 1 & 0 & 1 & 0 & 1 & 0 & 0 & 1 & 1 \\
\hline
\end{tabular}

Sehinggga akan membentuk bobot baru, adapun tabelnya adalah sebagai berikut:

Tabel 8. Bobot Baru

\section{Bobot Baru \\ Wbaru \\ $=$ wlama $+\Delta \mathbf{w}$ \\ $=$ blama $+\Delta \mathbf{b}$}

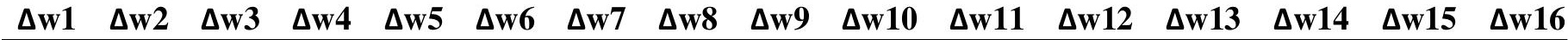

\begin{tabular}{llllllllllllllll}
0 & 0 & 0 & 0 & 0 & 0 & 0 & 0 & 0 & 0 & 0 & 0 & 0 & 0 & 0 & 0 \\
0 & 1 & 0 & 0 & 0 & 0 & 0 & 0 & 0 & 0 & 0 & 1 & 0 & 1 & 0 & 0 \\
0 & 1 & 0 & 0 & 0 & 0 & 0 & 0 & 0 & 0 & 0 & 0 & 1 & 1 & 0 & 0 \\
1 & 0 & 0 & 1 & 1 & 1 & 1 & 1 & 1 & 1 & 0 & 1 & 0 & 1 & 0 & 0 \\
\hline
\end{tabular}

Hasil akhir diambil dari nilai $\mathrm{w}_{1}=1, \mathrm{w}_{2}=0, \mathrm{w}_{3}=0, \mathrm{w}_{4}=1, \mathrm{w}_{5}=1, \mathrm{w}_{6}=1, \mathrm{w}_{7}=1, \mathrm{w}_{8}=1, \mathrm{w}_{9}=1, \mathrm{w}_{10}=1, \mathrm{w}_{11}=0, \mathrm{w}_{12}=1, \mathrm{w}_{13}=0$, $\mathrm{w}_{14}=1, \mathrm{w}_{15}=0, \mathrm{w}_{16}=0, \mathrm{w}_{17}=1, \mathrm{~b}=1$

Tabel 9. Masukan

\begin{tabular}{ccccccccccccccccc}
\hline $\mathbf{X 1}$ & $\mathbf{X 2}$ & $\mathbf{X 3}$ & $\mathbf{X 4}$ & $\mathbf{X 5}$ & $\mathbf{X 6}$ & $\mathbf{X 7}$ & $\mathbf{X 8}$ & $\mathbf{X 9}$ & $\mathbf{X 1 0}$ & $\mathbf{X 1 1}$ & $\mathbf{X 1 2}$ & $\mathbf{X 1 3}$ & $\mathbf{X 1 4}$ & $\mathbf{X 1 5}$ & $\mathbf{X 1 6}$ & X17 \\
\hline 0 & 1 & 0 & 0 & 0 & 0 & 0 & 0 & 0 & 0 & 0 & 1 & 0 & 1 & 0 & 0 & 0 \\
0 & 1 & 0 & 0 & 0 & 0 & 0 & 0 & 0 & 0 & 0 & 0 & 1 & 1 & 0 & 0 & 1 \\
0 & 1 & 1 & 0 & 0 & 1 & 0 & 0 & 0 & 0 & 0 & 0 & 0 & 1 & 0 & 0 & 0 \\
1 & 0 & 0 & 1 & 0 & 0 & 0 & 0 & 0 & 1 & 0 & 1 & 0 & 1 & 0 & 0 & 1 \\
\hline
\end{tabular}

Hasil Akhir: Net $=\sum_{i=1}^{17} x i w i+b$

Tabel 10. Hasil Akhir

\begin{tabular}{|c|c|}
\hline $\mathrm{n}=\mathrm{X}_{1} \mathrm{~W}_{1}+\mathrm{X}_{2} \mathrm{~W}_{2}+\mathrm{X}_{3} \mathrm{~W}_{3}+\mathrm{X}_{4} \mathrm{~W}_{4}+\mathrm{X}_{5} \mathrm{~W}_{5}+\mathrm{X}_{6} \mathrm{~W}_{6}+\mathrm{X}_{7} \mathrm{~W}_{7}+\mathrm{X}_{8} \mathrm{~W}_{8}+$ & $\mathrm{a}=\mathrm{f}(\mathrm{n})$ \\
$\mathrm{X}_{9} \mathrm{~W}_{9}+\mathrm{X}_{10} \mathrm{~W}_{10}+\mathrm{X}_{11} \mathrm{~W}_{11}+\mathrm{X}_{12} \mathrm{~W}_{12}+\mathrm{X}_{13} \mathrm{~W}_{13}+\mathrm{X}_{14} \mathrm{~W}_{14}+\mathrm{X}_{15} \mathrm{~W}_{15}+$ & $\mathrm{f}(\mathrm{n})=1, \mathrm{n} \geq 0$ \\
$\mathrm{X}_{16} \mathrm{~W}_{16}+\mathrm{X}_{17} \mathrm{~W}_{17}+\mathrm{b}=$ & $\mathrm{n}, \mathrm{n}<0$ \\
\hline 1 & $\begin{array}{l}0.1+1.0+0.0+0.1+0.1+0.1+0.1+0.1+0.1+0.1+0.0+ \\
1.1+0.0+1.1+0.0+0.0+0.1+1=3\end{array}$ \\
\hline
\end{tabular}




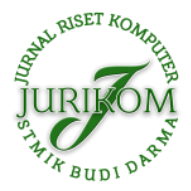

JURIKOM (Jurnal Riset Komputer), Vol. 7 No. 2, April 2020 e-ISSN 2715-7393 (Media Online), p-ISSN 2407-389X (Media Cetak)

\begin{tabular}{|l|l|c|}
\hline \multirow{2}{*}{2} & $0.1+1.0+0.0+0.1+0.1+0.1+0.1+0.1+0.1+0.1+0.0+$ & 1 \\
\hline \multirow{2}{*}{3} & $0.1+1.0+1.1+0.0+0.0+1.1+1=3$ & 1 \\
& $0.1+1.0+1.0+0.1+0.1+1.1+0.1+0.1+0.1+0.1+0.0+$ & 1 \\
\hline 4 & $\begin{array}{l}1.1+0.0+0.0+1.1+1.1+1.1+1.1+1.1+1.1+1.1+0.0+ \\
\end{array}$ & $1.1+0.0+1.1+0.0+0.0+1.1+1=12$
\end{tabular}

Tampak bahwa f(net) sama dengan target penyakit kolik abdomen, artinya bahwa jaringan dapat mengerti pola yang dimaksudkan. Bernilai 1 karena memakai pola bilangan biner, bukan bipolar.

\section{KESIMPULAN}

Adapun kesimpulan yang dapat diambil penulis dari hasil analisa, penerapan dan perancangan tersebut adalah sebagai berikut:

1. Pengguna dapat mengetahui sejauh mana gejalapenyakit kolik Abdomen pada orang dewasa.

2. Penerapan jaringan saraf tiruan dengan metode Hebb Rule dapat mendiagnosa penyakit Kolik Abdomen pada orang dewasa.

3. Perancangan program aplikasi jaringan saraf tiruan untuk mempermudah mengetahui penyakit kolik abdomen pada orang dewasa.

\section{REFERENCES}

[1] Y. Eninggar, "Pengenalan Huruf Braille Berbasis Jaringan Syaraf Tiruan Metode Hebb Rule," Universitas Diponegoro, Semarang, 2012.

[2] R. Muhammad dan D. Anita, Konsep Kecerdasan Buatan, Yogyakarta: Andi, 2006.

[3] Thorndika dan Hagen, 2011. [Online]. Available: http://id.scribd.com/doc/89963317/Pengertian-Diagnosias\#scribd..

[4] N. Syamsiah dan E. Muslihat, "Pengaruh Terapi Relakssi Autogenik Terhadap Tingkat Nyeri Akut Pada Pasien Abdominal pain Di IGD RSUD Karawang,” Jurnal Ilmu Keperawatan, vol. 3, pp. 1-17, 2014.

[5] Metode Belajar Hebbian Supervised, 2010. [Online].

[6] M. Salahuddin dan Rossa, Rekayasa Perangkat Lunak, Yogyakarta: Andi, 2010.

[7] M. Setyaningsih dan Emy, Kriptografi \& Implementasi menggunakan Matlab, Yogyakarta: Andi, 2015.

[8] “MySql,” MySQL, 2018. [Online]. Available: http://id.m.wikipeia.org/wiki/MySql. 